\title{
Developing the Competency of Mathematical Modelling: A Case Study of Teaching the Cosine and Sine Theorems
}

\author{
Duong Huu Tong, Nguyen Phu Loc, Bui Phuong Uyen \\ Can Tho University \\ Can Tho City, Vietnam \\ Le Thi Giang \\ Phan Thanh Giang High School \\ Ben Tre Province, Vietnam
}

\begin{abstract}
An important goal of teaching mathematics is to form and develop students' abilities to apply mathematical knowledge to solve problems arising from real life. This goal is also associated with the evaluation of specific mathematical competencies: mathematical thinking and reasoning, inference and proof, communication, modelling, problem solving and representation, using mathematical symbols and languages, using calculation tools. Among these competencies, modelling is the capacity mentioned by educators around the world and holds an increasingly important position in many popular mathematics programs of several countries. The objective of this study is to foster students' mathematical modelling competency through teaching sine and cosine theorems. The sample included 46 10th grade students at Phan Thanh Giang high school, Ben Tre province, Vietnam, and they were asked to solve numerous real-world problems associated with the theorems. The qualitative analysis method was used to evaluate students' performance in mathematical modelling competence. The results were found that most of the students made progress in mathematical modelling competency, from which they not only had the right motivation to learn but also supported them in realising the application of mathematics in practice.
\end{abstract}

Keywords: Competency; mathematical modelling; problem-solving; sine and cosine theorems.

\section{Introduction}

Many educators around the world do researches on modelling in teaching mathematics, and its scope of use is widespread, from elementary school to middle school, high school and even at the university level. The subjects of these 
studies may be students or teachers of schools, even preservice teachers at pedagogical universities. These ranges prove the critical significance of mathematical modelling in modern mathematics education.

Modelling in teaching mathematics is the process of facilitating students to learn and explore situations arising from real-life using mathematical tools and languages such as figures, tables, functions. Hence, modelling supports students in identifying the meaning and role of mathematical knowledge in life, elaborates on the ability to use mathematics to understand and solve practical matters (Alhammouri et al., 2019), so using mathematical modelling positively changes the mathematical literacy of the learners (Kanthawat et al., 2019). This process requires students to have mathematical skills and manipulations, such as analysis, synthesis, comparison, generalisation, and abstraction (Bahmaei, 2011). From here, modelling tasks contribute to the development of quantitative reasoning, problem-solving skills, so modelling competencies which are useful for real-world situations (Asempapa, 2015, 2018; Leong, 2013). For these reasons, it requires effective strategies to assist learners in strengthening mathematical modelling capability (Jung, 2015; Khusna \& Heryaningsih, 2018).

Applying modelling method into teaching will have advantages such as: creating opportunities for students to participate in solving real-world topics, not merely solving math problems; supporting students in learning mathematics in a meaningful motivating way and having passion for learning mathematics (Blum, 2009). Also, mathematical modelling is a process of using mathematical knowledge to new and strange situations, therefore, when performing mathematical modelling tasks, students may encounter lots of difficulties such as: not understanding the problem posed by real situations; defining assumptions, recognizing important variables to set up mathematical models; having limited mathematical knowledge, choosing an appropriate solution method as well as explaining the results (Carrejo \& Marshall, 2007; Bahmaei, 2011). Accordingly, it documented that students' ability to solve math problems is strongly related to modelling tasks (Fasni et al., 2017; Yuliani \& Kusumah, 2018).

In addition to the difficulties of mathematical modelling, there are some challenges when students and teachers use the modelling process in classrooms. There are not several real-world problems in textbooks for teachers to implement the modelling process. Consequently, the students will have difficulty in solving problems that are unfamiliar to them. Furthermore, students often have the negative psychology of encountering such troubles. Some other challenges belong to teachers. They have a limited career improvement, which entails their obstacle in designing real-world things to organise teaching in the process of modelling (Barquero, 2009). One possible reason for this is the absence of a mathematical modelling course in the teacher training curriculum. Also, teachers often do not have enough time due to the fixed and compulsory curriculum and the modelling process requires much time for both teachers and students. 
It can be said that the model is used to describe a practical situation, a mathematical model is understood as using mathematical tools to express it in the form of precise language, in which modelling is too the process of creating a model aims to solve a problem. This process follows a process that uses special rules to formulate hypotheses or mathematical structures such as formulas, algorithms, equations, tables, symbols, graphs, and then students have a more unobstructed view of problems that exist in practice.

There are many alternative definitions of researchers about modelling competencies, such as Maab (2006), who believe that modelling competency includes the skills and ability to implement the modelling process to achieve the goals. According to Kaiser (2005), the capacity of mathematical modelling is the ability to perform the entire process of mathematical modelling and reflect on that process. (cited by Blum (2009)). Based on the concept of Blum (1991), modelling skills can be interpreted as the ability to build models by performing various logical steps as well as analysing or evaluating proposed models. Six levels of modelling capability offered by Edu (2013) are as follows:

(1) Applying given models easily.

(2) Recognising, utilising and interpreting basic given models.

(3) Using distinct representational models.

(4) Working with explicit models and connecting constraints and assumptions.

(5) Developing and working with complex models; reflecting on modelling processes and outcomes.

(6) Conceptualising and working with models of complex mathematical processes and relationships reflect on, generalising and explaining modelling outcomes.

Almost authors give the process of mathematical modelling in their steps. For example, Hernández et al. (2017) proposed this model of 6 stages: identify the problem, make assumptions and identify variables, do the math, analyse and assess the solution, iterate, and implement the model. In the meantime, Dundar et al. (2012) provided aspects of the modelling that are associated with students' math topics: understanding, formalizing and applying the problems in diverse subject areas, employing the models by defining the simple relationships in the nature, and realizing the potentials and constraints of the models, commenting and discussing on the realities of the existing models and moving between the theoretical and practical aspects of modelling and problem-solving related to mathematics. Moreover, the researchers, Blum et al. (2009) also advanced a fourstage process for a modelling task: understanding tasks, establishing models, using mathematics, explaining the result. Meanwhile, Sekerák (2010) put forward more concise modelling with three steps: definition of model situation starting points, construction of a mathematical model and verification of the built model.

Ulu (2017) studied the modelling process of 22 fourth grade students by letting them solve the shopping problem. The findings demonstrated that some students were unable to provide realistic solutions because they did not notice 
the hidden actions in the situation. The remaining students were able to come up with practical solutions, and even they posed new problems by relying on the secret data in the given question. Similarly, English and Watters (2019) also had an analysis of modelling problems for 8-year-old students with teacher support. The findings revealed the student's progress on the following issues: sensemaking, problem posing, hypothesising and mathematising. Also, Ryanto et al. (2019) used the context of population growth in modelling tasks to teach mathematics to elementary students. They were introduced to the theory of modelling, and then they applied modelling jobs to solve matters; this process was documented on the prototype by the experts, mainly the student's explanation was also recorded to evaluate the influence of the research. It was apparent that mathematical modelling tasks related to the context of population growth were valuable, practical and useful.

Stohlmann (2017) studied the modelling capacities of middle school students associated with the robot art odel-eliciting activity. At first, the students had difficulty in communicating, but then thanks to the structure of the action that supported the quality of communication, from here the student groups came up with methods to set up robots to create a picture. Teachers combined this activity with mathematical modelling to assist students in building their understanding and expanding ideas. Another qualitative consideration of the difficulty of 83 9th grade students related to modelling problems in the PISA program was conducted by Edo et al. (2013). The writers used qualitative methods to evaluate students' performance to achieve research goals. Students' difficulties related to mathematical modelling included the establishment of mathematical situations and the ability to assess the validity of accurate solutions in the context of real-world topics. Also, a valuable record was that the student did not have obstacles while they solved mathematical problems.

Another 3-year investigation of 300 students based on the learning theory of mathematical modelling and problem-solving was constructed by Boaler (2001). It was documented that students made progress in areas such as working with textbook assignments, creating and using mathematical ideas, exploring diverse forms of math knowledge to put into practice to handle a wide range of situations and having a definite faith in learning mathematics. Also, Santos et al. (2015) had detailed scrutiny of the impact of integrating mathematical modelling on problem-solving skills and math concerns of 9th-grade students. In particular, the control group was taught by teachers' guidance, and the experimental group was organised with integrated mathematical modelling. Besides, the questionnaire and interview methods were also used to know more about students' behaviour when they participated in modelling tasks. After analysing the T-test, it was clear that the integration of mathematical modelling brought about significant effects, in which students upgraded their math problem-solving ability and their anxiety when they learned mathematics also decreased.

Lingefjard (2002) conducted an inquiry of preservice teachers about their application concerning real-life situations that had elements of mathematical 
modelling in the field of medicine. The majority of them seemed to prefer the relevant activity, but some preservice teachers also had a negative attitude about the complexity of the problem and their ability to respond to the situation. Furthermore, some of them expressed inaccuracies as well as misunderstood some hidden elements in the case. Besides, Supriadi et al. (2014) organised experiments to formulate the modelling competencies of 135 primary school preservice teachers. The experimental group was taught in ethno mathematicsbased context, while the control group was not. The analysis of outcomes was brought that the experimental group had better mathematical modelling competency than the control group thanks to the interaction between the learning model and cultural origin factors.

\section{Mathematical modelling in curriculum and textbooks in Vietnam}

In the mathematics curriculum, educators have emphasised: The mathematics program ensures the streamlining, practical and modern expression in reflecting the contents that must necessarily be mentioned in high schools, meeting the needs of world understanding as well as interests, learners' favourite, in line with the approach of today's world. The program thoroughly understands the spirit of "math for everyone", everyone can learn mathematics, but everyone can learn mathematics in an effective way that suits their interests and competencies.

Furthermore, the mathematics curriculum focuses on the applicability, relevance to practise or other subjects, educational activities, especially for themes to implement STEM education, in association with the modern development trend of the economy, science, social life and global pressing issues (such as climate change, sustainable growth, financial education, etc.). This is also reflected in practical activities and experiences in mathematics education in a variety of forms such as implementing math projects, especially subjects and projects regarding mathematics in real life; organizing math games, math clubs, forums, seminars, math contests to create opportunities for students to use their knowledge, skills, and experience in a really creative way.

One of the objectives of the curriculum is the formation and evolvement of mathematical competences, including mathematical thinking and reasoning; modelling; problem-solving; communication; using mathematical tools and means. Components of modelling ability are also explicitly stated by the curriculum as follows:

(1) Identifying mathematical models (including formulas, equations, tables, graphs) for situations that appear in real-world things.

(2) Solving numerical problems in an established model.

(3) Demonstrating and evaluating solutions in a real-world context and improving the model if the answer is not appropriate.

From here, it is also necessary to clarify the orientation for increasing students' mathematical modelling competencies in Vietnamese math textbooks associated with the topic of sine and cosine rules. 
In the formation of new knowledge, textbooks offer activities for teachers and students to review. Typically, these activities are very diverse to review the learnt knowledge, put a problem to new knowledge, and consider individual cases. Meanwhile, for practice, the textbooks propose mainly problems performing simple mathematical tasks. Nevertheless, there are also some practical problems, but most of them give a mathematical model, so students are only demanded to focus on their ability to solve math problems.

For Vietnamese textbooks, the teaching activities associated with the sine and cosine rules do not display the training of mathematical modelling capacity. The actual problem-solving activity is more realistic and very close to the mathematical model, it means that students are only interested in calculating to solve the problem, not involved in the transition from real data to a mathematical model to explain. Accordingly, the establishment of modelling capacity for students depends on the interest of teachers. From the attestation of content analysis in textbooks, it is realised that Vietnam's teaching institution has given some practical topics to train modelling capabilities for students, but most of them have attached models. This approach leads to students do not need to perform mathematical modelling procedures, and students also lose the opportunity to compare the results found with the actual situation of the problem. For this reason, if teachers want to train students the component competencies of mathematical modelling fully, they must learn and build appropriate circumstances for students.

In general, the development of mathematical modelling competencies for students has been focused only in recent years, particularly since the change in the general education program. Therefore, based on the theoretical and practical basis in teaching mathematics in Vietnam, research on this capacity building for students is vital to match the general trend of the world and the country, from there, it can meet the needs of innovation in education.

\section{Theoretical framework}

\subsection{Modelling process in teaching mathematics}

There are most of the originators offering various modelling teaching procedures. However, in this article, the modelling process and the steps of organising modelling activities are employed to train mathematical modelling competency for 10th-grade students through cosine and sine theorems. Based on the above modelling processes, the 7-step modelling process has been specified in Table 1.

Table 1: The steps of the mathematical modelling process

\begin{tabular}{|c|l|}
\hline Steps & \multicolumn{1}{|c|}{ Contents } \\
\hline 1 & $\begin{array}{l}\text { Exploring, analysing, simplifying the problem, identifying the assumptions of } \\
\text { the real-world topic. }\end{array}$ \\
\hline 2 & Establishing a link between the existing assumptions. \\
\hline 3 & $\begin{array}{l}\text { Selecting and using mathematical language to build problems describing } \\
\text { practical situations. }\end{array}$ \\
\hline 4 & Using mathematical tools and methods to solve problems. \\
\hline
\end{tabular}




\begin{tabular}{|c|l|}
\hline 5 & Understanding the meaning and solution of the problem in real-life situations. \\
\hline 6 & $\begin{array}{l}\text { Retesting the model, analysing the advantages and limitations of the model } \\
\text { already built. }\end{array}$ \\
\hline 7 & Noticing, explaining or improving the model under reality. \\
\hline
\end{tabular}

\subsection{Assessing mathematical modelling competency}

It is essential to base on the component competencies of mathematical modelling in mathematics general education curriculum in Vietnam to evaluate students' performance. Moreover, to ensure the feasibility of applying the assessment, the levels according to each criterion corresponding to each component capacity are raised in Table 2 as follows:

Table 2: The criteria and their levels to evaluate the mathematical modelling competency

\begin{tabular}{|c|c|c|c|c|}
\hline \multirow[t]{2}{*}{ Criteria } & \multicolumn{4}{|c|}{ Levels } \\
\hline & 1 & 2 & 3 & 4 \\
\hline $\begin{array}{c}1 \\
\text { Establishing a } \\
\text { relationship } \\
\text { between } \\
\text { assumptions made } \\
\text { in the situation }\end{array}$ & fail & $\begin{array}{l}\text { show a tiny } \\
\text { link between } \\
\text { assumptions }\end{array}$ & $\begin{array}{l}\text { express most of } \\
\text { the relationships } \\
\text { between the } \\
\text { assumptions, but } \\
\text { do not adequately } \\
\text { describe these } \\
\text { relationships }\end{array}$ & $\begin{array}{l}\text { build a } \\
\text { complete } \\
\text { model }\end{array}$ \\
\hline $\begin{array}{c}2 \\
\text { Selecting and using } \\
\text { mathematical } \\
\text { language to build } \\
\text { problems } \\
\text { describing real } \\
\text { situations } \\
\end{array}$ & $\begin{array}{l}\text { fail to state } \\
\text { mathematical } \\
\text { problem or } \\
\text { make a false } \\
\text { statement }\end{array}$ & $\begin{array}{l}\text { use minimal } \\
\text { mathematics } \\
\text { language to } \\
\text { report a } \\
\text { problem }\end{array}$ & $\begin{array}{l}\text { indicate the } \\
\text { problem but still, } \\
\text { have small errors }\end{array}$ & $\begin{array}{c}\text { accomplish } \\
\text { the } \\
\text { construction } \\
\text { of the problem }\end{array}$ \\
\hline $\begin{array}{c}3 \\
\text { Identifying the } \\
\text { mathematical } \\
\text { knowledge needed } \\
\text { to use to solve the } \\
\text { problem }\end{array}$ & $\begin{array}{l}\text { Do not find } \\
\text { any } \\
\text { mathematical } \\
\text { knowledge }\end{array}$ & $\begin{array}{l}\text { identify more } \\
\text { mathematical } \\
\text { knowledge to } \\
\text { use }\end{array}$ & $\begin{array}{l}\text { identify most } \\
\text { mathematical } \\
\text { knowledge } \\
\text { required but not } \\
\text { sufficient }\end{array}$ & $\begin{array}{l}\text { recognise all } \\
\text { the } \\
\text { mathematical } \\
\text { knowledge to } \\
\text { use }\end{array}$ \\
\hline $\begin{array}{c}4 \\
\text { Solving a math } \\
\text { problem }\end{array}$ & $\begin{array}{l}\text { fail to solve a } \\
\text { problem or } \\
\text { have the } \\
\text { wrong } \\
\text { solution }\end{array}$ & $\begin{array}{c}\text { explain } \\
\text { precisely a } \\
\text { small part of } \\
\text { the problem }\end{array}$ & $\begin{array}{l}\text { correctly answer } \\
\text { from } 2 / 3 \text { of the } \\
\text { problem's } \\
\text { requirements or } \\
\text { more }\end{array}$ & $\begin{array}{l}\text { complete } \\
\text { solving the } \\
\text { problem }\end{array}$ \\
\hline $\begin{array}{c}5 \\
\text { Understanding the } \\
\text { meaning, the } \\
\text { solution of the } \\
\text { problem to real-life } \\
\text { situations }\end{array}$ & $\begin{array}{c}\text { do not review } \\
\text { the solution } \\
\text { and results }\end{array}$ & $\begin{array}{l}\text { consider the } \\
\text { answer and do } \\
\text { not realise } \\
\text { whether the } \\
\text { results are } \\
\text { consistent with } \\
\text { the practical } \\
\text { problem or not }\end{array}$ & $\begin{array}{l}\text { evaluate the } \\
\text { solution and the } \\
\text { appropriate effect } \\
\text { suitable to the } \\
\text { actual problem }\end{array}$ & \\
\hline $\begin{array}{l}6 \\
\text { Answering the } \\
\text { situation }\end{array}$ & $\begin{array}{l}\text { can not } \\
\text { explain or } \\
\text { answer } \\
\text { wrongly }\end{array}$ & $\begin{array}{l}\text { answer the } \\
\text { situation's } \\
\text { questions } \\
\text { imperfectly }\end{array}$ & $\begin{array}{l}\text { correctly answer } \\
\text { the situation's } \\
\text { questions }\end{array}$ & \\
\hline
\end{tabular}


The primary purpose of this research is to enhance students' modelling competency through teaching the sine and cosine theorems. More specifically, the above modelling process and evaluation criteria are used to teach practical situations associated with the two mentioned theorems. Implicitly, this research also aims to assist students in realising the applicability of mathematics in real life, having the ability to use mathematics to solve real-world things, and training practical skills in individual activities and teamwork.

\section{Methods}

\subsection{Participants}

The experimental sample consisted of 46 students in class 10A1 Phan Thanh Gian High School, Ba Tri District, Ben Tre Province, Vietnam. This class was mentored by one of the authors, and this facilitated the organisation of experimental teaching and data acquisition. These students learned the theorems of sine and cosine, so they had necessary problem-solving skills related to these topics.

\subsection{Instruments}

Students were required to solve six real-world problems involving the sine and cosine theorems. Accurately, the information is presented in Table 3:

Table 3: The problems used in the stages

\begin{tabular}{|l|l|l|}
\hline \multicolumn{1}{|c|}{ Stages } & Problems used & \multicolumn{1}{c|}{ Contents } \\
\hline Pre-test & Problems 1, 2 & $\begin{array}{l}\text { Students do individually; to investigate students' } \\
\text { modelling competencies through solving two real- } \\
\text { world problems. }\end{array}$ \\
\hline $\begin{array}{l}\text { Teaching } \\
\text { according to } \\
\text { the 7-step } \\
\begin{array}{l}\text { modelling } \\
\text { process }\end{array}\end{array}$ & Problems 3,4 & $\begin{array}{l}\text { The teacher corrects two problems 1, 2; for problems } \\
3,4, \text { students work individually and in groups. }\end{array}$ \\
\hline Post-test & Problems 5,6 & $\begin{array}{l}\text { Students do individually; re-examine students' } \\
\text { modelling competencies; evaluate the effectiveness } \\
\text { of researchers' impacts }\end{array}$ \\
\hline
\end{tabular}

Problem 1: A reasonably vast lake at the corner created by two roads intersecting at point $A$. An intends to go from position $B$ to position $C$ by swimming across the lake. Knowing that the distance from $A$ to $B$ is $3 \mathrm{~km}$, the distance from $A$ to $C$ is $4 \mathrm{~km}, \widehat{\mathrm{BAC}}=120^{\circ}$, and the maximum swimming capacity of An is $6 \mathrm{~km}$. Please give sincere advice to An, should he swim across the lake or not?

Problem 2: A tree company needs to determine the height of a tree before cutting it down to make sure it will not fall on a nearby fence. The company sent two employees to measure the angle from the ground to the top of the tree, knowing that the two employees stood $12.2 \mathrm{~m}$ apart on the same line perpendicular to the height of the tree. The results of the first employee measure the angle $30^{\circ}$ and 
the second employee measure the angle of $20^{\circ}$. Can you help the company determine the height of the tree?

Problem 3: An aeroplane flies from Ho Chi Minh City to Nha Trang City with a distance of $308 \mathrm{~km}$, then changes the direction of the flight angle is $128,2^{\circ}$ from the original path and flies to Hanoi City with $1290 \mathrm{~km}$ range. If the plane flies directly from Ho Chi Minh City to Hanoi City, how far is the distance?

Problem 4: Assuming that the height of a mountain needs to be measured, the measurement person must determine the peak position by standing at two locations $900 \mathrm{~m}$ apart on the same line perpendicular to the height of the mountain. These two positions look at the top of the mountain at angles, respectively $35^{\circ}$ and $47^{\circ}$. Find the height of the mountain, knowing that the foot of the mountain is more than $2 \mathrm{~m}$ from the straight line?

Problem 5: A cargo ship maintained an average speed of $27.8 \mathrm{~km} / \mathrm{h}$ when travelling from Hai Phong port to Saigon port with a distance of $1500 \mathrm{~km}$. To avoid a tropical storm, the captain drove the ship out of Hai Phong port in the direction of $20^{\circ}$ going straight to the port of Saigon. The captain maintained a speed of $27.8 \mathrm{~km} / \mathrm{h}$ for 10 hours, then the road leading to the port of Saigon stopped the storm.

a) How many angles should the captain turn to go directly to Saigon port?

b) After turning, how long does it take for the ship to arrive at Saigon Port if the same speed of $27.8 \mathrm{~km} / \mathrm{h}$ is maintained?

Problem 6: Before tilting, the tower of Pisa was measured to be $56 \mathrm{~m}$ high. A person looked at the top of the tower and the base of the tower at an angle of $60^{\circ}$, knowing that this person stood $37.5 \mathrm{~m}$ from the foot of the tower. Calculate the tilt angle of the tower compared to the ground and the distance from the top of the tower to the ground after it was tilted?

The research design can be briefly stated as follows:

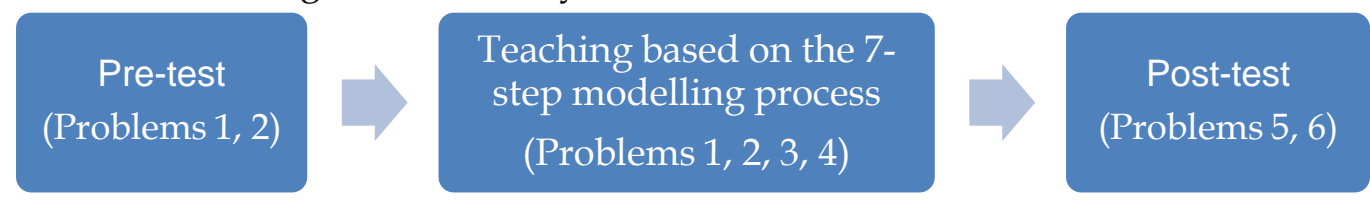

Figure 1: The process of research design

4.3 Experimental process of teaching based on the 7-step modelling process The experimental procedure was carried out in 3 phases:

Phase 1: Students follow the requirements in the experiment form in an original way prepared by the teacher. Time: 15 minutes.

The goal of phase 1: Students can express their capacity, think and solve situations. Students reveal modelling capabilities through the following steps: Building relationships between different factors that have been in the case, turning real-life problems with mathematical problems, solving math problems to solve situations, and considering the rationality of how to resolve situations. 
Phase 2: Students solve experimental situations done in phase 1 in the form of groups (the groups of 11 or 12 students) on the paper prepared by the teacher. Time: 10 minutes.

The goal of phase 2: Students review their work and comment on their work in the group. Thereby, the students discuss and present ideas to protect personal views or contribute to their work, absorbing the opinions of students in the group to complete the group's work together.

Phase 3: Validation - the class is still working in groups to correct lessons with the teacher. Each group sends representatives to present the work, and other groups comment and contribute ideas. The presentation group is refuted to give better achievements. The teacher then reviews each group's work and further guides the issues that the groups make mistakes, from which the work of each group is completed. Time: 20 minutes.

The goal of phase 3: Students will consider the results of group work in phase 2 in phase 3 with limited intervention by the teacher. This phase is a legalisation one of knowledge, assisting students in gradually improving modelling competencies.

Instructing students to perform modelling activities:

The teacher gives modelling process for students to refer and use two pre-test situations (the problems 1 and 2) to guide them in how to perform seven steps of organising modelling activities in the process (mentioned in the theoretical framework). In particular, steps 1 through 5 are mainly carried out in phase 1 , step 6 and step 7 in all three stages, but are clearly described in phase 2 and phase 3. Specifically, the instructions for each step and their goals are explained. To perform step 1, the teacher instructs students to read the situation and associate the problem in the case in reality. The teacher then asks students to state the main assumptions. In step 2, students are instructed to sketch the drawing for the situation and describe the outlined model. In step 3, students are taught to use mathematical language to express mathematical problems corresponding to the situation. In step 4, students apply the knowledge they have learned to solve math problems in step 3. Next, students are requested to understand the meaning and purpose of the solution and give answers to practical situations in step 5. Students review the topic, comment on the solution, discuss and comment in step 6. From there, students realise the advantages and limitations of the solution. In the final step, students are explained to assess practical problem-solving capacity, so they learn experience in the implementation process.

\subsection{Data analysis}

Students' assignments and worksheets were collected; from here, qualitative analytical methods are applied to evaluate students' modelling competency according to the criteria and levels are given in the theoretical framework. 


\section{Results and discussion}

\subsection{Pre-test results}

Table 4: Assessing student's modelling competency in the problems 1, 2 according to criteria 1,2

\begin{tabular}{|c|c|c|c|c|}
\hline \multirow{2}{*}{ Level } & \multicolumn{2}{|c|}{ Criterion 1 } & \multicolumn{2}{c|}{ Criterion 2 } \\
\cline { 2 - 5 } & $\begin{array}{c}\text { Problem 1 } \\
(\%)\end{array}$ & $\begin{array}{c}\text { Problem 2 } \\
(\%)\end{array}$ & $\begin{array}{c}\text { Problem 1 } \\
(\%)\end{array}$ & $\begin{array}{c}\text { Problem 2 } \\
(\%)\end{array}$ \\
\hline 1 & 17.39 & 28.26 & 28.26 & 34.78 \\
\hline 2 & 50 & 43.48 & 32.6 & 39.13 \\
\hline 3 & 1.57 & 23.91 & 30.14 & 15.22 \\
\hline 4 & 13.04 & 4.35 & 8.7 & 10.87 \\
\hline
\end{tabular}

Based on Table 4, the statistical findings indicated that the majority of students did not show or exhibited the minimal relationship between the factors that were in the situation. The rate of students assessed at level 1 and level 2 was $67.39 \%$ for case 1 and $71.74 \%$ in claim 2 . The student did not sketch a mathematical model describing the original real situation. The reason was able to be because they had few opportunities to utilise mathematics to solve practical cases. A small number of students who indicated the relationship between the assumptions already in practice did not pay attention to describing these relationships. The rate of students assessed at level 3 accounted for 1.57\% in problem 1 and $23.91 \%$ in problem 2 .

In the criteria for selecting and using mathematical language to build problems describing real situations, most students disclosed tiny, precise language to express the problems. Level 2 of this criterion accounted for $32.6 \%$ in case 1 and $39.13 \%$ in example 2. More interestingly, problem 1 had $28.26 \%$, and problem 2 had $34.78 \%$ of students who could not use mathematical language to convert actual problems to mathematical problems or convert them wrongly.

Table 5: Assessing student's modelling competency in the problems 1, 2 according to criteria 3,4

\begin{tabular}{|c|c|c|c|c|}
\hline \multirow{2}{*}{ Level } & \multicolumn{2}{|c|}{ Criterion 3 } & \multicolumn{2}{c|}{ Criterion 4 } \\
\cline { 2 - 5 } & $\begin{array}{c}\text { Problem 1 } \\
(\%)\end{array}$ & $\begin{array}{c}\text { Problem 2 } \\
(\%)\end{array}$ & $\begin{array}{c}\text { Problem 1 } \\
(\%)\end{array}$ & $\begin{array}{c}\text { Problem 2 } \\
(\%)\end{array}$ \\
\hline 1 & 32.61 & 21.74 & 52.17 & 32.61 \\
\hline 2 & 0 & 23.91 & 0 & 17.39 \\
\hline 3 & 0 & 15.22 & 13.04 & 39.13 \\
\hline 4 & 67.39 & 39.13 & 34.78 & 10.87 \\
\hline
\end{tabular}

The data from Table 5 indicated that most students were aware of all the mathematical knowledge needed to solve the problem, accounting for $67.39 \%$ in problem 1 and $39.13 \%$ in problem 2. Nevertheless, the number of students who solved the problem incorrectly was not small, in which case 1 was $52.17 \%$ and claim 2 was $32.61 \%$. 
Table 6: Assessing student's modelling competency in the problems 1, 2 according to criteria 5,6

\begin{tabular}{|c|c|c|c|c|}
\hline \multirow{2}{*}{ Level } & \multicolumn{2}{|c|}{ Criterion 5 } & \multicolumn{2}{c|}{ Criterion 6 } \\
\cline { 2 - 5 } & $\begin{array}{c}\text { Problem 1 } \\
(\%)\end{array}$ & $\begin{array}{c}\text { Problem 2 } \\
(\%)\end{array}$ & $\begin{array}{c}\text { Problem 1 } \\
(\%)\end{array}$ & $\begin{array}{c}\text { Problem 2 } \\
(\%)\end{array}$ \\
\hline 1 & 45.65 & 76.09 & 86.96 & 89.13 \\
\hline 2 & 28.26 & 0 & 0 & 0 \\
\hline 3 & 26.09 & 23.91 & 13.04 & 10.87 \\
\hline
\end{tabular}

Regarding the data in Table 6, at the step of understanding the meaning of the problem solution to the situation, in reality, were only $26.09 \%$ of students in the problem 1 and $23.91 \%$ of students in the problem 2 reviewed the settlement and recognised the results be consistent with the actual issue or not. Among students who paid attention to the conditions to answer questions for practical problems, several students still gave wrong answers to the situation. The rate of students giving wrong or no answers was $86.96 \%$ for problem 1 and $89.13 \%$ for problem 2. Regarding modelling capabilities, the outcomes of the two pre-test problems aided us in making some following remarks:

Many students did not yet achieve the capacity to set up mathematical models at levels 3 and 4. This information was reflected in the fact that students had not realised the relationship between mathematical knowledge and familiar situations in life. At the same time, students did not know how to use math language to turn practical situations into final form.

For the ability to resolve mathematical problems in the established model, the skills to recognise the mathematical knowledge to use and the problem-solving skills of students were quite good. Regarding the ability to explain the correctness of the solution, students did not have the habit of re-checking the work and had not reviewed the rationality of the solution to make necessary adjustments. Thus, if teachers do not pay attention to training mathematical modelling competencies for students, a large number of students will not see the meaningful role of mathematics in real life, and it can affect their interest in learning mathematics.

Pre-test findings also revealed that mathematical modelling proficiency of students only reached a low level. The reason was able to be that they were less exposed to problems with the content in practice and were not familiar with mathematical modelling activities. Correspondingly, teachers need to actively design materials about modelling capacity and take the initiative in creating mathematical modelling situations for teaching. 


\subsection{Results related to teaching according to the 7-step modelling process}

Table 7: Assessing student's modelling competency in Problem 3 according to 6 criteria when they worked individually

\begin{tabular}{|c|c|c|c|c|c|c|}
\hline \multirow{2}{*}{ Level } & \multicolumn{7}{|c|}{ Criteria } \\
\cline { 2 - 7 } & 1 & 2 & 3 & 4 & 5 & 6 \\
\hline 1 & 10.87 & 8.69 & 8.69 & 52.17 & 19.57 & 63.04 \\
\hline 2 & 41.31 & 43.48 & 0 & 0 & 32.6 & 0 \\
\hline 3 & 30.43 & 26.09 & 43.48 & 10.87 & 47.83 & 36.96 \\
\hline 4 & 17.39 & 21.74 & 47.83 & 36.96 & & \\
\hline
\end{tabular}

In the individual activities, for the criterion of establishing the relationship between assumptions from Table 7, the rate of students with proper assessment reached $47.83 \%$, increasing by $15.22 \%$ compared with the first problem and $19.57 \%$ compared with the problem 2 . Regarding the ability to express the problem, the number of students using mathematical language to describe practical situations was not good, accounting for a large proportion of $52.17 \%$. Some students could not identify the precise factors that appeared in the case of rewriting whole sentences in real situations.

Some common errors of students in this situation were not able to identify the corner of $128,2^{\circ}$ when the plane changed direction ( 24 students) and students did not pay attention to describing the established model.

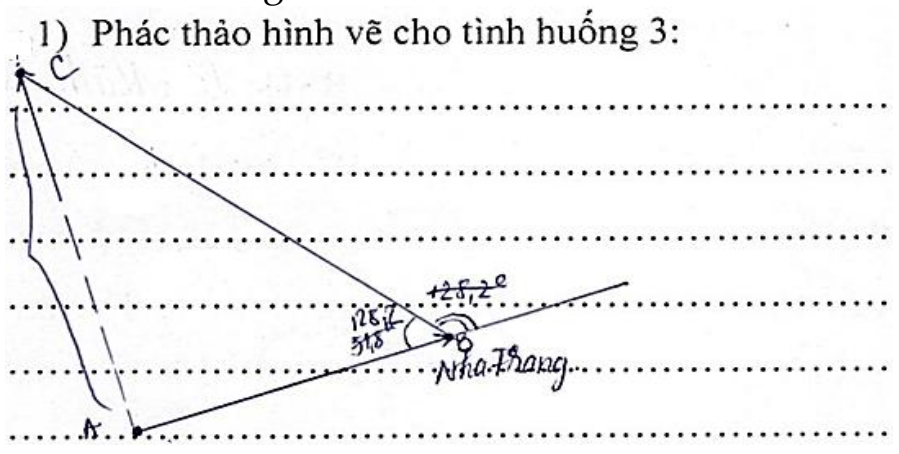

Figure 2: An illustration of the students' wrong solution

For the student's worksheet in Figure 2, he was puzzled in determining the angle with the measurement $128,2^{0}$; it was seen that through the first time, he discovered correctly but then left and chose the wrong angle. His worksheet revealed that he also did not pay attention to describe the established model. Thus, the ability to set students' models in this situation was not stable. The wrong identification of the object in the mathematical model caused students to incorrectly state the problem, make a mistake when solving the problem and failed to answer questions for the situation.

In the problem solving criteria, although the proportion of students who were not good at the problem accounted for $52.17 \%$ - not progressive compared to the two pre-test problems, but the rate of students achieving level 4 was $36.96 \%$ without significant increased compared with the problem 1 but increasing by 
$26.1 \%$ compared with the problem 2 . The percentage of students performing the step of answering questions for a situation effectively reached $36.96 \%$ corresponding to the rate of students solving the problem correctly.

In general, the mathematical modelling competency of students had not improved much compared to the two pre-test problems. Furthermore, over 50\% of students needed more training in building mathematical models. This step was a crucial component of mathematical modelling power. If students did not find the wrong mathematical model, it would affect the next steps in the modelling process.

Table 8: Assessing student's modelling competency in Problem 3 according to 6 criteria when they worked in groups

\begin{tabular}{|c|c|c|c|c|c|c|}
\hline \multirow{2}{*}{ Level } & \multicolumn{7}{|c|}{ Criteria } \\
\cline { 2 - 7 } & 1 & 2 & 3 & 4 & 5 & 6 \\
\hline 1 & 0 & 0 & 0 & 25 & 0 & 25 \\
\hline 2 & 25 & 0 & 0 & 0 & 0 & 0 \\
\hline 3 & 25 & 50 & 25 & 0 & 100 & 75 \\
\hline 4 & 50 & 50 & 75 & 75 & & \\
\hline
\end{tabular}

For phase 2, after discussion and adjustment, the groups achieved quite good performance in the first capacity due to the information in Table 8. There was still the group 1 sketching the wrong picture, the group 4 drawing the drawing correctly but not yet described. The percentage of the groups assessed at levels 3 and 4 for both criteria was $75 \%$ or more. Most groups were aware of the mathematical knowledge demanded to deal with the problem, and level 4 accounted for $75 \%$ for both criteria. There was still one group that had settled the question by determining the wrong angle when the plane changed direction.

Corresponding to the results of solving problems, the groups also performed efficiently in answering questions about the situation. The percentage of groups that responded to the question correctly accounted for $75 \%$, and only group 1 reacted incorrectly. This error also appeared in individual work because they identified the wrong object in the mathematical model.

In phase 3, the groups discussed a lot about the angle determination of $128,2^{\circ}$ and the description of the mathematical model. When group 1 finished the presentation, the other groups contributed their ideas on the drawing of the situation along with the statement of the problem which the group 1 countered. The reasoning of the group 2 persuaded the members of group 1 to note ideas and learn from experience. In this situation, the answer to the original problem was the calculated solution to the math problem. Consequently, the students only wanted to write conclusions according to the context of the problem without having to argue more. 
Table 9: Assessing student's modelling competency in Problem 4 according to 6 criteria when they worked individually

\begin{tabular}{|c|c|c|c|c|c|c|}
\hline \multirow{2}{*}{ Level } & \multicolumn{7}{|c|}{ Criteria } \\
\cline { 2 - 7 } & 1 & 2 & 3 & 4 & 5 & 6 \\
\hline 1 & 4.35 & 4,35 & 6.52 & 6.52 & 19.57 & 52.17 \\
\hline 2 & 17.39 & 19.57 & 2.18 & 13.04 & 21.74 & 0 \\
\hline 3 & 50 & 23.91 & 17.39 & 26.09 & 58.69 & 47.83 \\
\hline 4 & 28.26 & 52.17 & 73.91 & 54.35 & & \\
\hline
\end{tabular}

Table 9 provided information on evaluating the student's modelling performance associated with problem 4 . Compared with the problem 3 , the rate of students showing the relationship between assumptions at level 3 and level 4 increased by more than $30.44 \%$, the percentage of students using math language to build the problems at level 4 increased over $30.43 \%$. In the criteria for recognising the mathematical knowledge to be used, the rate of students assessed at level 1 and level 2 did not decrease compared to the problem 3, but the price of students estimated at level 4 increased by $26.08 \%$. Regarding the ability to cope with challenges, the percentage of students failing to solve the problems dropped significantly. Although the rate of good math students increased, the percentage of students who correctly answered the questions of the problem had not increased significantly. The reason was that students had to understand the meaning and solution of the problem to have the right answer. Thus, the modelling competency of students in this situation was more advanced than the problem 3 . The most evident was the capacity to set up mathematical models.

There were still two students who were not actively thinking, exploiting real elements in the situation, thus failing to establish mathematical models and not presenting mathematical problems. Meanwhile, some students also misinterpreted the model as the work of the following student in Figure 3.

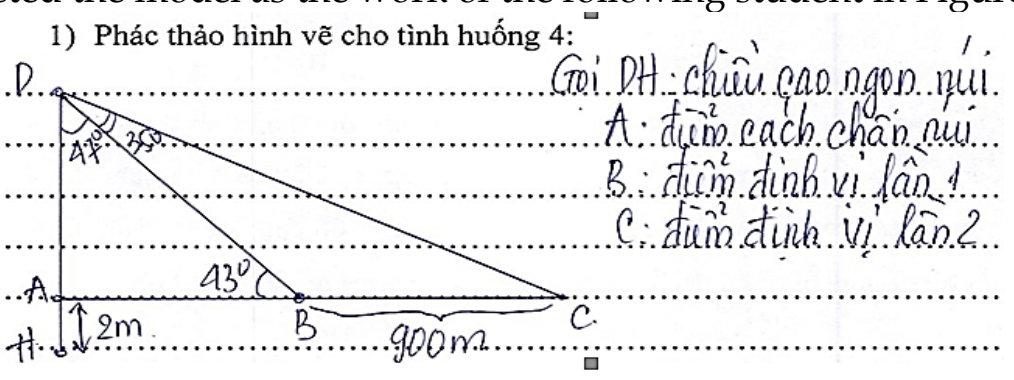

Figure 3: An illustration of the students' wrong solution

Table 10: Assessing student's modelling competency in Problem 4 according to 6 criteria when they worked in groups

\begin{tabular}{|c|c|c|c|c|c|c|}
\hline \multirow{2}{*}{ Level } & \multicolumn{7}{|c|}{ Criteria } \\
\cline { 2 - 7 } & 1 & 2 & 3 & 4 & 5 & 6 \\
\hline 1 & 0 & 0 & 0 & 0 & 0 & 0 \\
\hline 2 & 0 & 0 & 0 & 0 & 0 & 0 \\
\hline 3 & 50 & 25 & 0 & 0 & 100 & 100 \\
\hline 4 & 50 & 75 & 100 & 100 & & \\
\hline
\end{tabular}


From the parameters of Table 10, most groups had overcome the mistakes of individual work, so no group work had reached levels 1 and 2. Two groups had not adequately described the relationship between assumptions in mathematical models and a group that lacked assumptions in the problem statement. With the ability to resolve math problems, all four groups had performed in the right way, and level 4 reached $100 \%$. It was revealed that the groups worked in problem 4 more effectively than they did in problem 3 . Nonetheless, there were still some students in group 2 who had not actively participated in group activities. With this problem, all groups understood the meaning and the solution to the problem, so they answered the situation very correctly.

In the working part of phase 3 of the groups, students mainly gave ideas to each other to complete the step of establishing the relationship between assumptions in the situation and the stage of answering questions for the job. Besides, students also discussed different ways to solve problems. During the exchange, students discovered their mistakes about how to set up the model, as mentioned in phase 1. After being commented and explained by the teacher, these students realised what the right model suitable for the situation was.

\subsection{Post-test results}

Table 11: Assessing student's modelling competency in the problems 5, 6 according to criteria 1,2

\begin{tabular}{|c|c|c|c|c|}
\hline \multirow{2}{*}{ Level } & \multicolumn{2}{|c|}{ Criterion 1 } & \multicolumn{2}{c|}{ Criterion 2 } \\
\cline { 2 - 5 } & $\begin{array}{c}\text { Problem 5 } \\
(\%)\end{array}$ & $\begin{array}{c}\text { Problem 6 } \\
(\%)\end{array}$ & $\begin{array}{c}\text { Problem 5 } \\
(\%)\end{array}$ & $\begin{array}{c}\text { Problem 6 } \\
(\%)\end{array}$ \\
\hline 1 & 0 & 0 & 0 & 0 \\
\hline 2 & 6.67 & 2.22 & 6.67 & 2.22 \\
\hline 3 & 31.11 & 15.56 & 33.33 & 11.11 \\
\hline 4 & 62.22 & 8.22 & 60 & 86.67 \\
\hline
\end{tabular}

According to Table 11, students had established the relationship between assumptions gradually over two post-test problems. Individually, the students were assessed mainly at level 4 , with over $62 \%$ for both issues. Students also showed their ability to use mathematical language to build better questions when the ratio of students who completed the mathematical problem 5 reached $60 \%$, and this ratio in problem 6 reached $86.67 \%$. Some students were assessed at level 2 and level 3 due to the following reasons: they did not see all the mathematical elements appearing in the situation, identified the wrong object in the model, could not write all the assumptions in real situations about mathematical form, re-expressed incomplete mathematical model. 
Table 12: Assessing student's modelling competency in the problems 5, 6 according to criteria 3,4

\begin{tabular}{|c|c|c|c|c|}
\hline \multirow{2}{*}{ Level } & \multicolumn{2}{|c|}{ Criterion 3 } & \multicolumn{2}{c|}{ Criterion 4 } \\
\cline { 2 - 5 } & $\begin{array}{c}\text { Problem 5 } \\
(\%)\end{array}$ & $\begin{array}{c}\text { Problem 6 } \\
(\%)\end{array}$ & $\begin{array}{c}\text { Problem 5 } \\
(\%)\end{array}$ & $\begin{array}{c}\text { Problem 6 } \\
(\%)\end{array}$ \\
\hline 1 & 0 & 0 & 0 & 0 \\
\hline 2 & 6.67 & 0 & 8.89 & 4.44 \\
\hline 3 & 22.22 & 8.89 & 26.67 & 11.11 \\
\hline 4 & 71.11 & 91.11 & 64.44 & 84.45 \\
\hline
\end{tabular}

The ability to identify mathematical knowledge to be used by students was sensitive; in particular, most of them had an excellent performance in solving problems. The rate of students solving problems at level 3 and level 4 for both problems was over $90 \%$. However, there were still a small number of students who could only solve the problem at level 2 . The reason was that they thought that the problem was strange, so they did not know how to deal with it.

Table 13: Assessing student's modelling competency in the problems 5,6 according to criteria 5,6

\begin{tabular}{|c|c|c|c|c|}
\hline \multirow{2}{*}{ Level } & \multicolumn{2}{|c|}{ Criterion 5 } & \multicolumn{2}{c|}{ Criterion 6 } \\
\cline { 2 - 5 } & $\begin{array}{c}\text { Problem 5 } \\
(\%)\end{array}$ & $\begin{array}{c}\text { Problem 6 } \\
(\%)\end{array}$ & $\begin{array}{c}\text { Problem 5 } \\
(\%)\end{array}$ & $\begin{array}{c}\text { Problem 6 } \\
(\%)\end{array}$ \\
\hline 1 & 0 & 0 & 0 & 0 \\
\hline 2 & 8.89 & 4.44 & 11.11 & 17.78 \\
\hline 3 & 31.11 & 0 & 28.89 & 0 \\
\hline 4 & 60 & 95.56 & 60 & 82.22 \\
\hline
\end{tabular}

The student's performance in the problems was reported that the student had shown a quite stable ability to analyse and understand the meaning of the solution to give a solution to the situation. The rate of students with the correct questions for problem 5 was $60 \%$, and this ratio in problem 6 was $82.22 \%$. Also, the students had difficulty in giving answers to the situation, in which the proportion in problem 5 was $11.11 \%$, and the ratio in problem 6 was $17.78 \%$.

\section{Conclusion}

Through practical conditions, the mathematical modelling competencies of many students had made progress, but there were still some students who had not progressed. For these students, teachers were necessary to enhance practical problems that suited their ability and spent much time supporting them in their implementation. Experiment findings proved that 10th-grade students could perform mathematical modelling skills in the case of teaching quantitative systems in triangles. This method not only aided them in the right motivation for learning but also gave support to them to realise the applicability of mathematics in practice. The experimental process was believed that most 
students applied the modelling process to elucidate practical situations. These values are similar to other research results (Edo et al., 2013; Stohlmann, 2017; Ulu, 2017). A small number of students still had difficulties and embarrassment in finding mathematical models and the transition from real-world problems to math problems, and these difficulties are also raised in Edo's research (2013). In the form of group organisation, they were created conditions to communicate with each other in order to give them a hand identifying their shortcomings.

The introduction of real-world situations for students to see the limitations of the built model, from which students have to return to find a new mathematical model more suitable is essential. At the same time, teachers can also choose such situations to ask students to come up with two separate mathematical models, but this depends on the level and awareness of students. From the analysis of students' performance on mathematical modelling competence, some implications associated with its value are drawn. Mathematical modelling activities will assist students in enhancing thinking manipulations and problemsolving skills, from which students understand the relationship between mathematics and the surrounding environment and other science subjects, helping the learning process becomes meaningful. Mathematical modelling is characterized by the context in which students are required to explore knowledge through mathematics or other interdisciplinary real-life situations. Therefore, integrating daily practical situations into classroom teaching situations is very important to show students the practical applicability of mathematics. Thus, with mathematical knowledge, teachers can use models to explain and help students understand real-life phenomena. Specific mathematical models such as graphs, tables, equations, systems of equations denote aspects in nature and society. Also, using the modelling method in teaching supports learners in promoting mathematical skills, and it also helps teachers organise teaching in a more effective way of detecting and solving problems. Alternatively, this method makes students' math learning more meaningful by enhancing and clarifying mathematical elements in practice. The ability to analyse and solve practical problems is also considered when using this method because the stages of the modelling process help to practice mathematical thinking operations, namely, analysis, synthesis, abstraction, visualisation, generalisation, comparison, analogy, systematisation, specialisation, deduction, and induction. Regarding the attitudes and beliefs of students, the modelling method to strengthen the spirit of cooperation in learning, independence and confidence for them through group discussions.

Students' mathematical modelling skill is closely linked to their problem-solving ability because they wish to cope with math problems during the modelling process, from which their competencies more solidly consolidated. Additionally, the modelling tasks provide an opportunity for them to re-consider the relationship "mathematics is derived from the practice and then mathematics is used to solve other practical problems". As a result, the students increasingly see the full range of practical applications of mathematics, and this is also in line with the current trend of Realistic Mathematics Education (RME) (Zakaria \& Syamaun, 2017). 
Moreover, educators' cognitive change has included practical math problems in math curricula and textbooks, and it is necessary to intensify these problems in tests instead of simple math problems. This approach will lead to a progressive change in the attitude of teachers and students in learning mathematics. In Vietnam, the modelling method is still entirely new to teachers when teaching mathematics. There have not been many kinds of research on utilising this method in teaching and learning mathematics in high schools. From here, there is also a requirement for more research on teachers' perceptions of teaching by mathematical modelling (Lingefjard, 2002; Carrejo \& Marshall, 2007; Supriadi et al., 2014). A large number of studies also show the importance of modelling in math education, so in the professional progression of teachers, they are also trained in teaching methods of mathematical modelling, even if there is a course on this subject in the teacher training curriculum (Baquero et al., 2009).

\section{References}

Alhammouri, A., Durkee, J., \& Foley, G. D. (2019). Where to place a post? Engaging students in mathematical modelling process. Ohio Journal of School Mathematics, $75,41-48$.

Asempapa, R. S. (2018). Mathematical modelling: an important concept in mathematics education. Journal of Education and Practice, 9(24), 136-143.

Asempapa, R. S. (2015). Mathematical modelling: essential for elementary and middle school students. Journal of Mathematics Education, 8(1), 18-29.

Bahmaei, F. (2011). Mathematical modelling in primary schools, advantages, and challenges. Journal of Mathematical Modelling and Application, 1(9), 3-13. doi:10.1.1.850.3848

Baquero, B., Bosch, M. \& Gascón, J. (2009). The ecology of mathematical modelling: constraints to its teaching at university level. Proceedings of CERME 6, January 28th-February 1st 2009, Lyon France C INRP 2010, 2146-2155.

Blum, W. \& Ferri, R. B. (2009). Mathematical modelling: can it be taught and learnt?. Journal of Mathematical Modelling and Application, 1(1), 45-58.

Blum, W. \& Niss, M. (1991). Applied mathematical problem solving, modelling, applications, and links to other subjects - state, trends, and issues in mathematics instruction. Educational Studies in Mathematics, 22(1), 37-68. doi: $10.1007 /$ bf00302716

Boaler, J. (2001). Mathematical modelling and new theories of learning. Teaching Mathematics and its Applications, 20(3), 121-218. doi:10.1093/teamat/20.3.121

Carrejo, D. J., \& Marshall, J. (2007). What is mathematical modelling? Exploring prospective teachers' use of experiments to connect mathematics to the study of motion. Mathematics Education Research Journal, 19(1), 45-76. doi:10.1007/bf03217449.

Dundar, S., Gokkurt, B., \& Soylu, J. (2012). Mathematical modelling at a glance: a theoretical study. Procedia- Social and Behavioral Sciences, 46, 3465-3470.

Edo, S. I., Hartono, Y., \& Putri, R. I. I. (2013). Investigating secondary school students' difficulties in modelling problems, PISA-model levels 5 and 6. IndoMS. J.M.E, 4(1), 41-58. doi:10.1016/j.sbspro.2012.06.086

English, L. D., \& Watters, J. J. (2004). Mathematical modelling with young children. Proceedings of the 28th Conference of the International Group for the Psychology of Mathematics Education, 2, 335-342. 
Fasni, N., Turmudi, T., \& Kusnandi, K. (2017). Mathematical problem-solving ability of junior high school students through Ang's framework for mathematical modelling instruction. Journal of Physics: Conf. Series, 895, 1-5. doi:10.1088/17426596/895/1/012082

Hernández, M. L., Lavy, R., Felton-Koestler, M. D., \& Zbiek, R. M. (2017). Mathematical modelling in the high school curriculum. Mathematics Teacher, 110(5), 336-342. doi:10.5951/mathteacher.110.5.0336

Jung, H. (2015). Strategies to Support Students' Mathematical Modelling. Mathematics Teaching in the Middle School, 21(1), 42-48. doi:10.5951/mathteacmiddscho.21.1.0042

Kanthawat, C., Supap, W., \& Klin-eam, C. (2019). The development of grade 11 students' mathematical literacy on sequences and series using mathematical modelling. Journal of Physics: Conf. Series, 1157, 1-6. doi:10.1088/1742-6596/1157/3/032100

Khusna, H., \& Heryaningsih, N. Y. (2018). The influence of mathematics learning using SAVI approach on junior high school students' mathematical modelling ability. Journal of Physics: Conf. Series, 948, 1-4. doi:10.1088/1742-6596/948/1/012009

Leong, K. E. (2013). Mathematical modelling in the Malaysia secondary school curriculum. Learning Science and Mathematics, 8, 66-74.

Lingefjard, T. (2002). Mathematical modelling for preservice teachers: a problem from anesthesiology. International Journal of Computers for Mathematics Learning, 7, 117143.

Maab, K. (2006). What are modelling competencies?. International Journal on Mathematics Education, 38(2), 113-142. doi:10.1007/bf02655885

Ryanto, B., Zulkardi, Putri, R. I. I., \& Darmawijoyo. (2019). Learning mathematics through modelling tasks in elementary school: using growth of population context. Journal of Physics: Conference Series, 1166, 1-8. doi:10.1088/17426596/1166/1/012033

Santos, M. L. K. P., Diaz, R. V., \& Belecina, R. R. (2015). Mathematical modelling: effects on problem-solving performance and math anxiety of students. International Letters of Social and Humanistic Sciences, 65, 103-115. doi:10.18052/www.scipress.com/ilshs.65.103

Sekerák, J. (2010). Phases of mathematical modelling and competence of high school students. The teaching of Mathematics, 8(2), 105-112.

Stohlmann, M. S. (2017). Mathematical modelling with middle school students: The robot art model-eliciting activity. European Journal of STEM Education, 2(4), 1-13. doi:10.20897/ejsteme.201704.

Supriadi, Suryadi, D., Sumarmo, U., \& C. Rakhmat. (2014). Developing mathematical modelling ability students elementary school teacher education through ethno mathematics-based contextual learning. International Journal of Education and Research, 2(8), 439-452.

Ulu, M. (2017). Examining the mathematical modelling processes of primary school 4th-Grade students: shopping problem. Universal Journal of Educational Research, 5(4), 561-580. doi:10.13189/ujer.2017.050406

Yuliani, A., \& Kusumah, Y. S. (2018). Analysis of mathematical modelling ability of line equations of junior high school students. Journal of Physics: Conf. Series, 1132, 1-8. doi:10.1088/1742-6596/1132/1/012045

Zakaria, E., \& Syamaun, M. (2017). The effect of realistic mathematics education approach on students' achievement and attitudes towards mathematics. Mathematics Education Trends and Research, 2017(1), 32-40. doi:10.5899/2017/metr-00093 